\title{
Preface of the "Symposium on Operational Research and Applications"
}

\author{
Fernanda A. Ferreira and Flávio Ferreira \\ ESEIG.IPP, Applied Management Research Unit (UNIAG), Polytechnic Institute of Porto \\ Rua D. Sancho I, 981, 4480-876 Vila do Conde, Portugal. \\ E-Mail: \{fernandaamelia, flavioferreira\}@eu.ipp.pt
}

\begin{abstract}
The aim of the symposium is to bring together researchers with different backgrounds and interests in all aspects of Operational Research, its application in Industrial Organization, and its practice, in order to further communication, collaboration, and exchange of new ideas. This symposium welcomes all researchers, academicians, practitioners, as well as students interested in any branch of operational research. The topics include, but are not limited to the following: Optimization methods, Decision theory, Stochastic models, Simulation, Game theory, Queueing systems, Combinatorial Optimization, Cutting and Packing, Data mining, Optimal control, Transportation, Multi-objective optimization, Scheduling, and other.
\end{abstract}

\section{Fernanda A. Ferreira}

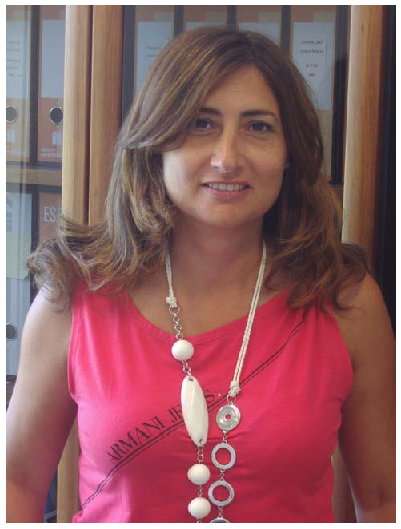

Fernanda A. Ferreira is member of the Applied Management Research Unit (UNIAG) and Adjunct Professor of Mathematics at School of Management and Industrial Studies, Polytechnic Institute of Porto (Portugal). She got her $\mathrm{PhD}$ at University of Porto in 2007, with a thesis entitled "Applications of Mathematics to Industrial Organization", under the supervision of Alberto A. Pinto. Her research interests are in Game Theory and its applications in Industrial Organization. She is the author or co-author of more than 50 journal papers and conference proceedings. She has given talks in major international conferences, mainly on Mathematics and its applications in Engineering and Economics.

\section{Flávio Ferreira}

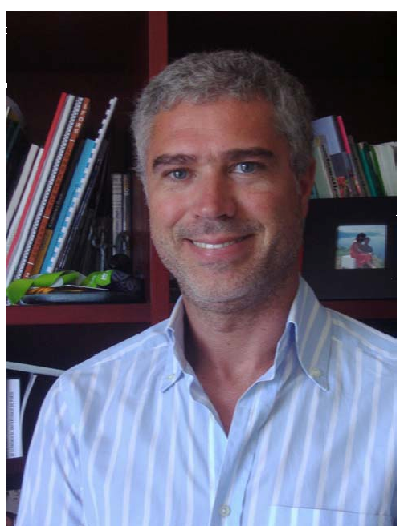

Flávio Ferreira is member of the Applied Management Research Unit (UNIAG) and Full Professor of Mathematics at School of Management and Industrial Studies, Polytechnic Institute of Porto (Portugal). He is the Dean of the School of Management and Industrial Studies, Polytechnic Institute of Porto. He got his PhD in Applied Mathematics, at University of Porto, in 2000, under the supervision of Alberto A. Pinto. His research interests are in Dynamical Systems and in Game Theory and its applications in Industrial Organization. He is co-author of a book published by Springer-Verlag, and co-author of more than 40 journal papers and conference proceedings. 